\title{
Integration of High Accuracy N-Terminus Identification in Peptide Sequencing and Comparative Protein Analysis Via Isothiocyanate-Based Isotope Labeling Reagent with ESI Ion-trap TOF MS
}

\author{
Jiapeng Leng, ${ }^{1}$ Haoyang Wang, ${ }^{1}$ Li Zhang, ${ }^{1}$ Jing Zhang, ${ }^{1}$ Hang Wang, ${ }^{1}$ Tingting Cai, ${ }^{1}$ \\ Jinting Yao, ${ }^{2}$ Yinlong Guo ${ }^{1}$ \\ ${ }^{1}$ Shanghai Mass Spectrometry Center, Shanghai Institute of Organic Chemistry, Chinese Academy of Sciences, \\ 345 Lingling Rd., Shanghai 200032, China \\ ${ }^{2}$ Shimadzu Global COE for Application and Technical Development, Shanghai, China
}

\begin{abstract}
A multifunctional isothiocyanate-based isotope labeling reagent, $\left[d_{0}\right]-/\left[d_{6}\right]-4,6$-dimethoxy pyrimidine2-isothiocyanate (DMPITC), has been developed for accurate N-terminus identification in peptide sequencing and comparative protein analysis by ESI Ion-trap TOF mass spectrometry. In contrast with the conventional labeling reagent phenyl isothiocyanate (PITC), DMPITC showed more desirable properties such as rapid labeling, sensitivity enhancement, and facilitating peptide sequencing. More significantly, DMPITC-based labeling strategy possessed the capacity of higher reliable $\mathrm{N}$-terminus identification owning to the high-yield $\mathrm{b}_{1}$ ion combined with the isotope validation of $6 \mathrm{Da}$. Meanwhile, it also showed potential in differentiating isomeric residues of leucine and isoleucine at $\mathrm{N}$-terminus on the basis of the relative abundance ratios between the fragment ions of their respective $b_{1}$ ions. The strategy not only allows accurate interpretation for peptide but also ensures rapid and sensitive comparative analysis for protein by direct MS analysis. Using trypsindigested bovine serum albumin (BSA), both peptide $\mathrm{N}$-terminus identification and quantitative analysis were accomplished with high accuracy, efficiency, and reproducibility. The application of DMPITC-based labeling strategy is expected to serve as a promising tool for proteome research.
\end{abstract}

Key words: 4,6-dimethoxy pyrimidine-2-isothiocyanate, Isotope labeling, N-terminus identification, b1 ions, Comparative protein analysis

\section{Introduction}

Chemical labeling focused on N-terminus of peptides remarkably induces the formation of ions, e.g., $b_{1}$ or $a_{1}$,

Electronic supplementary material The online version of this article (doi:10.1007/s13361-011-0129-5) contains supplementary material, which is available to authorized users.

Correspondence to: Yinlong Guo; e-mail: ylguo@sioc.ac.cn in tandem mass spectrometry (MS/MS) illustrating the identities of N-terminus [1-4]. As an important constraint, $\mathrm{N}$-terminal residues effectively promote the accuracy of peptide sequencing in MS-based proteomics [3-12]. They are not only treated as the "sequence or mass tag" to enhance the matching score of peptides in database (e.g., sequence query in Mascot), but also can be utilized to validate the positive sequences and screening candidate list. Consequently, improved peptide sequencing results in highly confident identification of proteins. 
For $\mathrm{a}_{1}$ ions, Chen and coworkers firstly reported a method to enhance their signals by N-terminal dimethylation [3]. Cai et al. investigated that peptides labeled by iodoacetamide at N-terminus also yield abundant $a_{1}$ ions [4]. For the wider applied $b_{1}$ ions, on the other hand, phenyl isothiocyanate (PITC) enables them to be obviously detected owning to the collision activated dissociation of N-terminal phenylthiocarbamoyl (PTC) protonated peptide, which is known as the gas-phase Edman cleavage [1,2]. Taking the advantages of this specific cleavage induced by PITC, variety of studies, such as N-terminus determination, peptide sequencing, and protein identification as well as quantification have been accomplished successfully [13-18]. For instance, Marshall et al. characterized trypsin-digested apomyoglobin labeled with PITC by Fourier transform ion cyclotron resonance (FT-ICR) MS [13]. Oliver et al. accurately identified yeast proteins labeled with PITC by gel electrophoresis and MALDI-MS [14]. More recently, Oe and coworkers studied the quantitation of bovine serum albumin (BSA) without a protein standard by analyzing the phenylthiohydantoin derivative-Asp released from the N-terminus [17].

Despite benefiting from the conventional methods in the identification of $\mathrm{N}$-terminus, some problems still restrict their further applications in MS or MS/MS analysis mainly from the following causes. PITC labeled peptides often show reduced sensitivity compared with the unlabeled peptides. Another labeling reagent, 4-sulfophenyl isothiocyanate (SPITC) used for N-terminal sulfonation, also leads to decreased sensitivity of which labeled peptides as well as $b_{1}$ ions in positive ion mode, resulting from the sulfonic group [19]. Certain $b_{1}$ and $a_{1}$ ions still can not be accurately assigned due to their relative weak signals intermixed with other fragment ions nearby in the low mass range. Besides, exploring convenient approach for differentiation of leucine and isoleucine residues at $\mathrm{N}$-terminus is still an important and appealing research direction [2026]. For the above reasons, it is highly desirable to develop the innovative methods for high accuracy N-terminus analysis.

As we formerly reported, $\left[d_{0}\right]-/\left[d_{6}\right]-4,6$-dimethoxy-2(methylsulfonyl)pyrimidine (DMMSP) has been applied as protein modification reagent with high reactivity and sensitivity owing to the introduction of pyrimidine ring [27-30]. Herein, coupling the superiorities of PITC and DMMSP, we present a multifunctional isotope labeling reagent $\left[d_{0}\right]-/\left[d_{6}\right]-4,6$-dimethoxy-pyrimidine-2-isothiocyanate (DMPITC) aimed at accurate N-terminus identification in peptide sequencing and comparative protein analysis. Compared with PITC (Scheme 1), except accelerating labeling rate, enhancing MS signal and facilitating peptide sequencing, overall features of DMPITC-based labeling strategy used for proteome research were demonstrated.

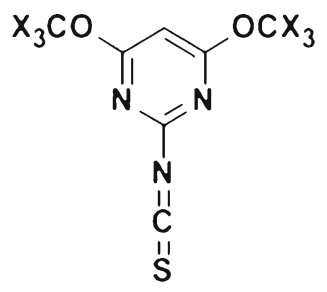

$\left[d_{0}\right]$ - DMPITC $: \mathrm{X}=\mathbf{H}$

$\left[d_{6}\right]$-DMPITC : $\mathrm{X}=\mathrm{D}$

Scheme 1. Chemical structures of designed isotope labeling reagent DMPITC and conventional labeling reagent PITC

\section{Experimental}

\section{Materials and Reagents}

2-Amino-4,6-dichloropyrimidine (98\%), thiophosgene (90\%) were obtained from Sigma Aldrich (St. Louis, MO, USA). Methanol- $d_{4}(99.8 \% \mathrm{D}$ of atom) was purchased from Cambridge Isotope Laboratories, Inc. (Boston, MA). Synthesized peptides (DRVYIHPF, DRVYIHPFHL, and EGVNDNEEGFFSAR), phenyl isothiocyanate (PITC), trypsin (TPCKtreated), and bovine serum albumin (BSA) were also purchased from Sigma Aldrich (St. Louis, MO, USA). Synthesized peptides (LDR and IDR) were obtained from Shanghai Bootech Bioscience and Technology Co. Ltd. (Shanghai, China). Deionized water was produced by a Direct-Q water purification system (Millipore, El Paso, TX). Other chemicals were all of analytical grade and used without further purification.

\section{Syntheses of $\left[d_{0}\right]-/\left[d_{6}\right]-$ DMPITC}

The synthetic procedures of the 'light' and 'heavy' DMPITC were optimized based partly on previous published papers [31, 32]. 2-Amino-4,6-dichloropyrimidine ( $500 \mathrm{mg}, 2.5 \mathrm{mmol}$ ), dissolved in $10 \mathrm{~mL}$ of anhydrous methanol, was added drop wise to a solution of $200 \mathrm{mg}$ of sodium metal in $20 \mathrm{~mL}$ of anhydrous methanol. (For preparation of the $\left[d_{6}\right]$-product, methanol- $d_{4}$ was used instead of anhydrous methanol.) The reaction mixture was stirred overnight at $25{ }^{\circ} \mathrm{C}$, then filtered and concentrated in vacuum. The residue was taken up in $10 \mathrm{ml}$ of water and extracted with dichloromethane $(3 \times 5 \mathrm{~mL})$. The combined extracts were dried over sodium sulfate and concentrated in vacuum, giving the crude product $\left[d_{0}\right]-$ or $\left[d_{6}\right]$-4,6-dimethoxypyrimidin-2- amino.

To a mixture of $\left[d_{0}\right]$ - or $\left[d_{6}\right]$-4,6-dimethoxypyrimidin-2amino (745 mg, $4.8 \mathrm{mmol}$ ) and sodium hydrogen carbonate $(1 \mathrm{~g}, 12 \mathrm{mmol})$ in $20 \mathrm{~mL}$ of anhydrous dichloromethane was added a solution of thiophosgene $(0.36 \mathrm{~mL}, 4.8 \mathrm{mmol})$ with mild stirring. After the mixture was heated at reflux temperature for $6 \mathrm{~h}$, the mixture was poured into water, and the product was extracted with dichloromethane $(3 \times$ $40 \mathrm{~mL}$ ). The organic layers were combined, dried over magnesium sulfate and concentrated to give the crude 
product. The residue was subjected to column chromatography (silica gel, ethyl acetate/hexanes, 1:6 vol/vol), affording $\left[d_{0}\right]-$ or $\left[d_{6}\right]$-DMPITC $(426 \mathrm{mg}, 45 \%)$ as yellow solid. The flow chart of synthesis route is shown in the Supplementary Material Scheme S1).

The structure of $\left[d_{0}\right]$-DMPITC was confirmed as follows: ${ }^{1} \mathrm{H}-\mathrm{NMR}\left(\mathrm{CDCl}_{3}, 300 \mathrm{MHz}\right): \delta=5.94(\mathrm{~s}, 1 \mathrm{H}), 3.94(\mathrm{~s}, 6 \mathrm{H})$; ${ }^{13} \mathrm{C}-\mathrm{NMR}\left(\mathrm{CDCl}_{3}, 75 \mathrm{MHz}\right): \delta=172.4,152.3,145.0,89.0$, 54.7; IR (neat, $\mathrm{cm}^{-1}$ ): 2013, 1610, 1543, 1402, 1354, 1201, 1063, 848, 681. HR MS (ESI): $\mathrm{m} / z$ calcd for $\mathrm{C} 7 \mathrm{H} 8 \mathrm{~N} 3 \mathrm{O} 2 \mathrm{~S}^{+}$ $[\mathrm{M}+\mathrm{H}]^{+}$198.0337, found: 198.0332 .

The structure of $\left[d_{6}\right]$-DMPITC was confirmed as follows: ${ }^{1} \mathrm{H}-\mathrm{NMR}\left(\mathrm{CDCl}_{3}, 300 \mathrm{MHz}\right): \delta=5.91(\mathrm{~s}, 1 \mathrm{H}) ;{ }^{13} \mathrm{C}-\mathrm{NMR}$ $\left(\mathrm{CDCl}_{3}, 75 \mathrm{MHz}\right): \delta=172.5,152.3,145.0,89.0,54.9$; IR (neat, $\mathrm{cm}^{-1}$ ): 2007, 1636, 1544, 1437, 1356, 1207, 1091, 848, 658; HR MS (ESI): $\mathrm{m} / \mathrm{z}$ calcd for C7H2D6N3O2S ${ }^{+}$ $[\mathrm{M}+\mathrm{H}]^{+}$204.0714, found: 204.0708.

\section{Chemical Labeling of Peptides and Protein}

The peptides $(50 \mu \mathrm{L}, 100 \mathrm{pmol} / \mu \mathrm{L})$ was reacted with labeling reagent $(50 \mu \mathrm{L}, 50 \mathrm{nmol} / \mu \mathrm{L})$ in $300 \mu \mathrm{L}$ of solution containing pyridine, ethanol and deionized water $(2: 2: 1 \mathrm{vol} /$ $\mathrm{vol} / \mathrm{vol}$ ) at $55^{\circ} \mathrm{C}$ for $90 \mathrm{~min}$. The reaction was terminated by cooling the system to $0{ }^{\circ} \mathrm{C}$. Then, the mixture was dried with nitrogen. The dried powder was dissolved with $200 \mu \mathrm{L}$ water and dichloromethane $(1: 1 \mathrm{vol} / \mathrm{vol})$. Excess labeling regent was eluted by the organic layer. The aqueous layer was dried completely by SpeedVac for mass spectrometry analysis. For the chemical labeling of BSA, $1 \mathrm{mg}$ of the protein was firstly digested with trypsin $(50: 1 \mathrm{wt} / \mathrm{wt})$ in $1 \mathrm{~mL}$ of the $\mathrm{NH}_{4} \mathrm{HCO}_{3}$ buffer solution containing $8 \mathrm{M}$ urea $(\mathrm{pH} 8.0-8.2)$ at $37{ }^{\circ} \mathrm{C}$ overnight. An amount of $50 \mu \mathrm{L}$ of the reaction solution was then mixed with $50 \mu \mathrm{L}$ of DMPITC $(80 \mathrm{nmol} / \mu \mathrm{L})$ solution underwent chemical labeling following the same procedure described. To evaluate the utility of DMPITC for comparative protein analysis, two aliquots of tryptic peptides from BSA were labeled separately with light and heavy DMPITC. After drying in a Speed-Vac, the peptide mixture was maintained at $-20{ }^{\circ} \mathrm{C}$ until required for further MS/MS experiments.

\section{$L C-M S^{n}$ Analysis}

The LC-MS ${ }^{n}$ analysis was performed on a liquid chromatography ion-trap time-of-flight mass spectrometer (LC-ITTOF/MS) (Shimazu, Tokyo, Japan). A potential of $4.0 \mathrm{kV}$ was applied to the electrospray ion source. The detection voltage was set as $1.65 \mathrm{kV}$. MS/MS spectra were obtained in the positive-ion mode with optimized collision energy. Intensity trends for the ions of $b_{1}$ and $y_{13}$ from EGVNDNEEGFFSAR was acquired with different collision energy $(5,10,15,20,30,40,50,60$, and $70 \%)$, All spectra were obtained by combining MS scans acquired within $1 \mathrm{~min}$. The acquisition of data was performed on Labsolution data system (Tokyo, Japan) (ver. 3.50). Resulting MS/MS and
MS/MS/MS data were interpreted manually. External mass calibration was performed by sodium trifluoroacetate. Labeled peptides or peptide mixtures were resuspended in $50 \%$ acetonitrile contained $(0.1 \%$, vol $/ \mathrm{vol})$ trifluoroacetic acid to a final concentration of $40-60 \mathrm{pmol} / \mu \mathrm{L}$. The samples were introduced into the mass spectrometer with $70 \%$ acetonitrile at a flow rate of $0.1 \mathrm{~mL} / \mathrm{min}$. For the differentiation experiment of $\mathrm{N}$-terminally isomeric residues, $\left[d_{0}\right]$-DMPITC labeled BSA digest were injected directly onto a $2.1 \mathrm{~mm} \times$ $15 \mathrm{~cm}$ column packed with C18 material (Agilent Zorbax SB$\mathrm{C} 18,5 \mu \mathrm{m}, 300 \AA)$. Peptides were eluted at a flow rate of $0.2 \mathrm{~mL} / \mathrm{min}$ with mobile phase A $(99.9 \%$ water, $0.1 \%$ formic acid), to which mobile phase B ( $100 \%$ acetonitrile) was added by a linear gradient (increased from $5 \%$ to $70 \%$ B within $30 \mathrm{~min}$ ). The MS experiment was performed under conditions as described above.

\section{Results and Discussion}

\section{Synthesis of $\left[d_{0}\right]-/\left[d_{6}\right]-D M P I T C$}

We developed an optimum two-step approach based partially on previous synthetic work [31,32]. In short, the synthesis of DMPITC was achieved by treating the commercially available 2-amino-4,6-dichloropyrimidine with excess sodium metal in methanol, followed by a nucleophilic substitution with thiophosgene in dichloromethane. The 'light' or 'heavy' form of the labeling reagent could be conveniently acquired with good yield by isotopically different solvents (methanol- $d_{0}$ or methanol- $d_{4}$, respectively). All the chemical materials were inexpensive and readily available. The fairly mild and straightforward synthetic route did not require any special techniques in favor of the practical application of DMPITC in MS-based proteomics.

\section{DMPITC: Higher Labeling Efficiency and Enhanced Sensitivity}

In this study, we presented the designed DMPITC to enhance the performance of $\mathrm{N}$-terminus analysis for peptides from chemical labeling to MS and MS/MS detection encountering the intrinsic problems of the conventional labeling reagent PITC. For comparison, model peptide DRVYIHPF (AngiotensinII) was reacted with PITC and $\left[d_{0}\right]$-DMPITC, respectively, under an identical labeling condition. As shown in Figure 1a and b, other than the incomplete labeling reaction of PITC, only single mass peak corresponding to DMPITC labeled peptide $[\mathrm{M}+2 \mathrm{H}]^{2+}$ at $\mathrm{m} / \mathrm{z}$ 622.3 was detected by ESI mass spectrometry. This result indicated that DMPITC possessed a higher labeling efficiency than the conventional labeling reagent PITC. Besides, it was found that the peak intensity of PITC labeled analyte was smaller than the original peptide not undergoing labeling (Figure 1c) because the basic amino group at $\mathrm{N}$-terminus was hindered by nonpolar phenyl group. Meanwhile, the precipitation of some modified peptides was also responsible for the 


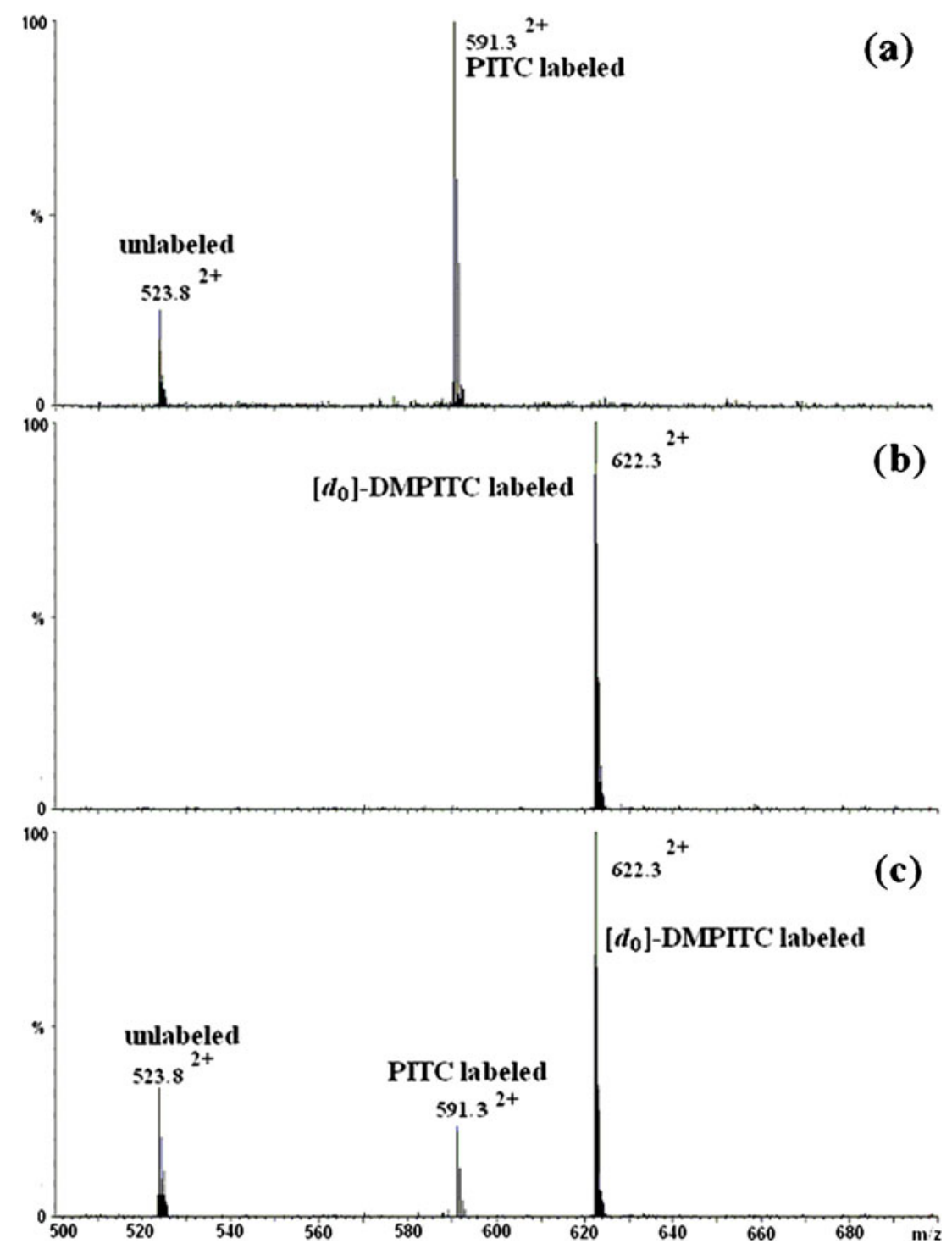

Figure 1. Mass spectra of different labeling reagents reacting with model peptide DRVYIHPF: (a) PITC labeled, (b) $\left[d_{0}\right]-$ DMPITC labeled, (c) mixture of unlabeled, PITC and $\left[d_{0}\right]$-DMPITC labeled model peptide DRVYIHPF at same molar concentration

loss of signal intensity [13]. Encouragingly, DMPITC labeled peptide gave rise to a signal with 2.5-3.5 times stronger than unlabeled and PITC labeled peptides at the same molar concentration. All the priorities of DMPITC are attributed to the advanced structure, 4,6-dimethoxy-pyrimidine, which is a medium electron withdrawing group instead of phenyl in PITC [33, 34]. ${ }^{13} \mathrm{C}-\mathrm{NMR}$ spectra of DMPITC and PITC revealed that chemical shift of carbon atom $(145.0 \mathrm{ppm})$ located in the isothiocyanate of DMPITC moved to low field with a $9.5 \mathrm{ppm}$ shift compared with that of carbon atom (135.5 ppm) in PITC. Therefore, DMPITC labels faster in dynamics because the reactive site already turns into a stronger nucleophilic receiver. Pyrimidine ring provides the labeled peptide a higher proton affinity, which efficiently enhances the ionization efficiency and sensitivity, facilitating the trace detection of low-abundance peptides. In addition, the charge state of peptides $(2+)$ was largely unchanged during the process of ionization owning to the relatively small molecule weight of DMPITC. There was no obvious signal optimization of labeled peptides when they were desalted prior to MS detection.

\section{Specific Fragmentation of DMPITC Labeled Peptides: Yielding $b_{1}$ Ion}

Figure 2 exhibited that $\left[d_{0}\right]$-DMPITC labeled peptide EGVNDNEEGFFSAR (Glu-fibrinopeptide, $\left[\begin{array}{ll}M+2 & \mathrm{H}\end{array}\right]^{2+}$ ) yielded dominant $\mathrm{b}_{1}$ ion at $m / z 327.1$ and sequential y ions at $40 \%$ collision energy. Paying close attention to the low mass range, protonated $\left[d_{0}\right]$-DMPITC at $\mathrm{m} / z 198.0$ detached from Nterminally labeled peptide could be regarded as a reporter ion in favor of validating the chemical labeling. Generally speaking, the formation of $b_{1}$ ion undergoes gas-phase Edman-type cleavage, which is promoted by nucleophilic attack on the first 


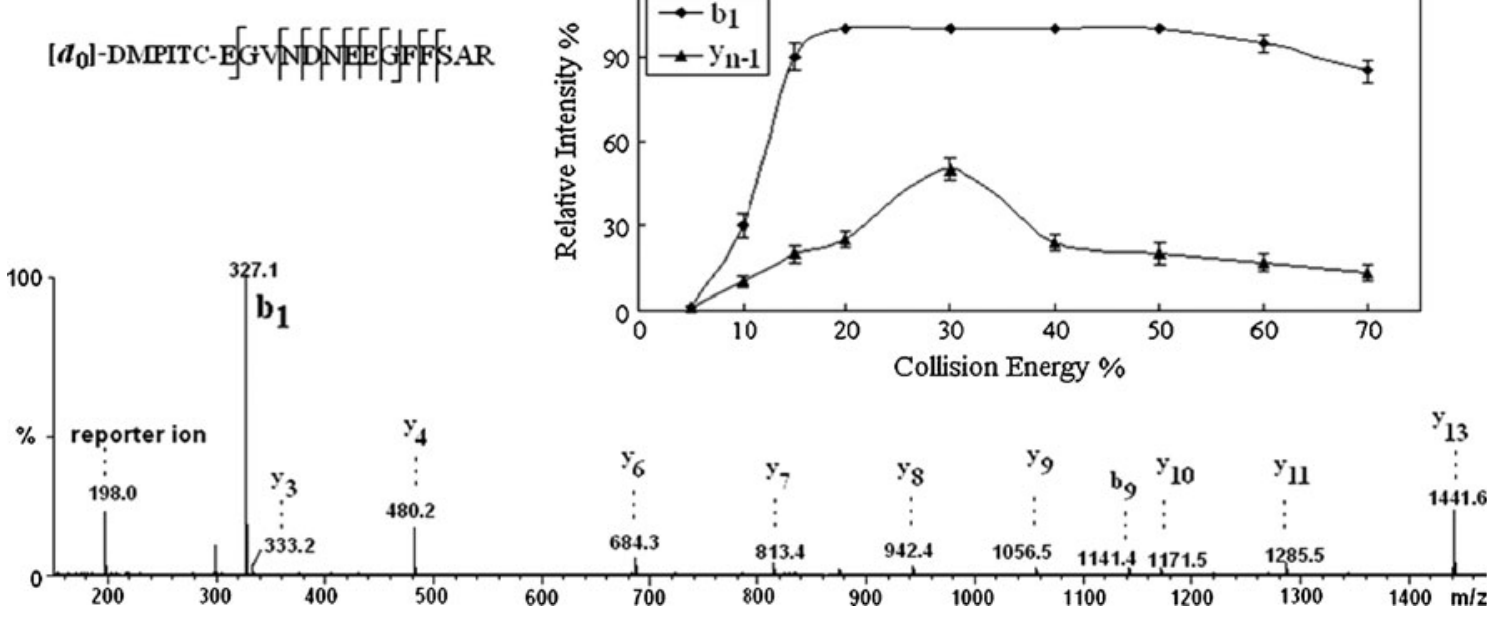

Figure 2. MS/MS spectrum of $\left[d_{0}\right]$-DMPITC labeled peptide EGVNDNEEGFFSAR and the relative intensity trends for $b_{1}$ ion and $\mathrm{y}_{\mathrm{n}-1}\left(\mathrm{y}_{13}\right)$ ion of $\left[d_{0}\right]$-DMPITC labeled peptide EGVNDNEEGFFSAR under changed collision energy (data points are mean \pm $\mathrm{SD}$ from three replicates for each collision induce dissociation CID)

carbonyl group of N-terminal peptide backbone from the thiocarbonyl of PITC analogs. Thus, as the major complementary moiety of $\mathrm{b}_{1}$ ion, $\mathrm{y}_{\mathrm{n}-1}\left(\mathrm{y}_{13}\right)$ ion at $m / z 1441.6$ also derived from the gas-phase cleavage, while for the peak intensities of newly emerged $b_{1}$ ion and its counterparts in positive ion mode MS, protons contained in their molecules should be taken into consideration. Pyrimidine ring in DMPITC as a proton affinity group retained more protons for generated $b_{1}$ ion during the process of collision induced dissociation (CID). This effect particularly is embodied in the persistently high intensity of $b_{1}$ ion along with the amplified collision energy (up to 70\%) compared with the peak intensity of complementary $\mathrm{y}_{13}$ ion (inset of Figure 2). The signal of $b_{1}$ ion reached highest intensity at very low collision energy of $20 \%$, indicating the high efficiency of gas-phase cleavage induced by DMPITC. Wang et al. also found that the subsistent of isothiocyanate with basic groups could promote the Edman-type fragmentation compared with unlabeled peptides [35]. Therefore, all these features demonstrated the excellent performance of DMPITC in enhancing the sensitivity and stability focused on $b_{1}$ ions. Moreover, the sequential y ions in the MS/MS spectrum are also valuable for the peptide sequencing of unknown sequence, as well as narrowing down the candidate list.

\section{Identifying $N$-Terminal Residues of Peptides with DMPITC Induced $b_{1}$ Ion}

Although PITC and other labeling reagents are utilized for the identification of $\mathrm{N}$-terminal residues, certain $\mathrm{b}_{1}$ or $\mathrm{a}_{1}$ ions still ca not be easily identified due to their relative weak signals intermixed with other fragment ions nearby in the low mass range. For instance, only an unobvious $b_{1}$ ion at $m / z$ 251.1 (Figure 3a) of PITC labeled peptide DRVYIHPFHL (Angiotensin $\mathrm{I},[\mathrm{M}+2 \mathrm{H}]^{2+}$ ) was found in the low mass range at $35 \%$ collision energy, which probably led to an ambiguous recognition. In order to avoid the occurrence of incorrect attribution of $b_{1}$ ion, we established an effective method to promote the accuracy based on $\left[d_{0}\right]-/\left[d_{6}\right]$-DMPITC. As shown in Figure $3 \mathrm{~b}$ and $\mathrm{c}$, both $\left[d_{0}\right]-$ and $\left[d_{6}\right]$-DMPITC induced the peptides to generate abundant $b_{1}$ ions. Compared with $\left[d_{0}\right]$-DMPITC labeled peptide, $\left[d_{6}\right]$-DMPITC labeled peptide produced 6 Da-added $\mathrm{b}$ ions, while $\mathrm{y}$ ions of unchanged mass. Thereby, the $b_{1}$ ion was undoubtedly identified on the basis of the enhanced signal and 6 Da mass difference. The identity of N-terminal residue (aspartic acid) was accurately assigned by a 115 Da mass deviation between $b_{1}$ ion and reporter ion. More ions (e.g., sequential $b$ ions and $\mathrm{y}_{3}, \mathrm{y}_{4}, \mathrm{y}_{8}, \mathrm{y}_{9}$ ions), meanwhile, were also easily acquired according to the isotope mass differences, which could serve as the assistant information for peptide sequencing. The ions at $\mathrm{m} / \mathrm{z} 198.0$ and 204.1 in the low mass range were then in favor of repeated recognizing of DMPITC labeled peptides. The method applied in the recognition of fragment ions based on isotope labeling was also implemented by previous studies, which demonstrated the feasibility of our strategy focused on high accuracy N-terminus identification [36-38]. Additionally, similar to PITC labeled peptide in the MS/MS spectrum, certain DMPITC labeled peptides were also observed to generate fragment ions of losing entire and partial (aniline for PITC, 4,6-dimethoxypyrimidine-2-amine for DMPITC) labeling reagents, named by $\mathrm{O}$ and $\mathrm{N}$, respectively.

It should be pointed out that the unique pair of isomeric residues (Leu and Ile) in 20 common amino acids gives virtually indistinguishable mass at $113.1 \mathrm{Da}$. There were limited reports about the mass spectrometric methods to distinguish Ile and Leu residues in previous studies [20-26]. Bowie et al. identified the isomeric residues between Ile and Leu by the characteristic decompositions of the $[\mathrm{M}-\mathrm{H}]^{-}$ ions of their phenylthiohydantoin (PTH) derivatives from sequential Edman degradation [22]. Armirotti et al. proposed a method to distinguish these two amino acids by $\mathrm{MS}^{n}$ induced diagnostic ion at $\mathrm{m} / \mathrm{z} 69$ and tested it on a 


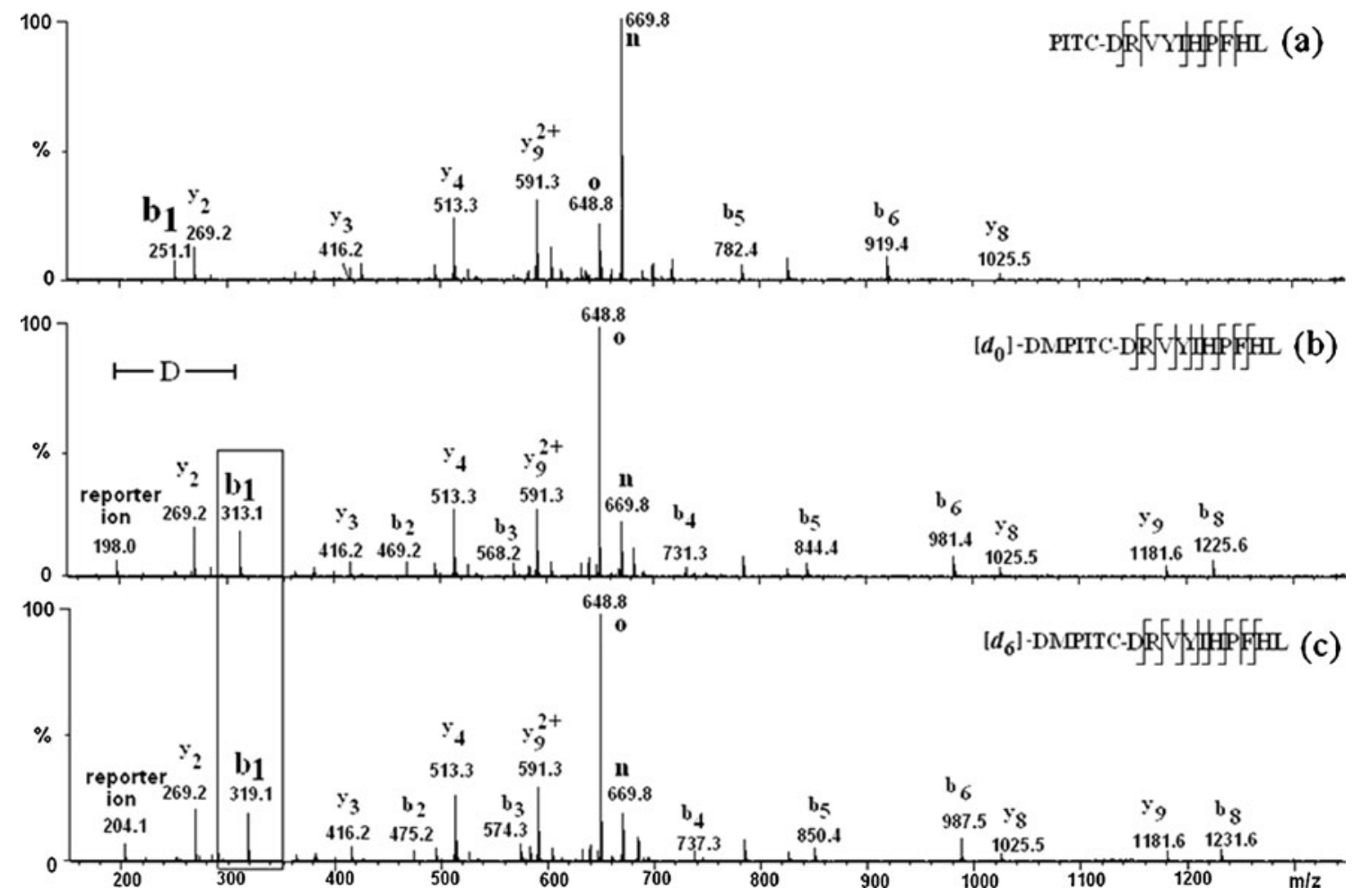

Figure 3. MS/MS spectra of DMPITC labeled peptide DRVYIHPFHL: (a) PITC labeled, (b) [ $\left.d_{0}\right]-D M P I T C ~ l a b e l e d, ~(c) ~\left[d_{6}\right]-$ DMPITC labeled (the box highlights $b_{1}$ ions)

myoglobin digest assigning the majority of the peptides [25]. More recently, Soltwisch and Dreisewerd found that the dand w-type fragment ions of peptides from high-energy side chain cleavage also allowed for the differentiation of isomeric residues [26]. Here, without complicated procedure, residues of Leu and Ile at N-terminus were differentiated rapidly on the basis of the relative abundance ratios between the fragment ions of their respective $b_{1}$ ions using ion trap-time of flight MS. As shown in Figure 4, two $\left[d_{0}\right]-$ DMPITC labeled peptides (IDR and LDR) with N-terminally isomeric residues were employed to produce $b_{1}$ ions with identical mass at $\mathrm{m} / \mathrm{z} 311.1$ (the insets indicate $\mathrm{MS}^{3}$ processes). The relative abundance ratios between the
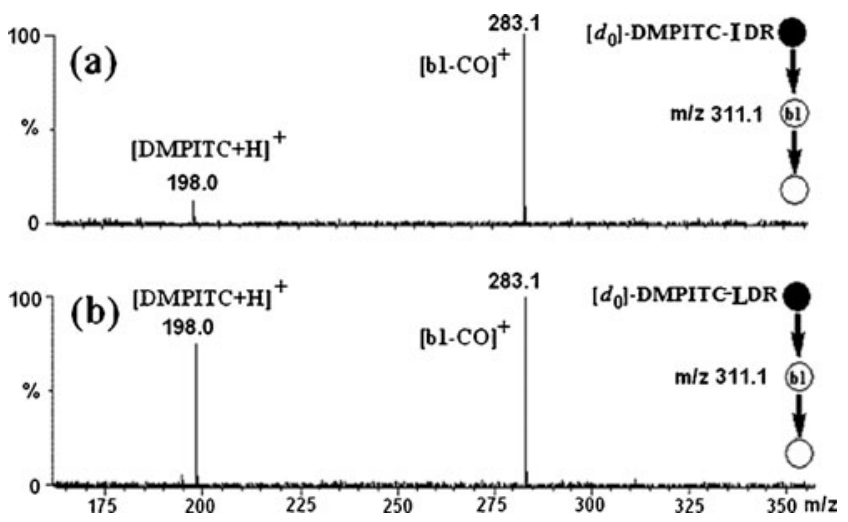

Figure 4. MS/MS/MS spectra of $\left[d_{0}\right]$-DMPITC labeled peptides with $\mathrm{N}$-terminally residues of Leu and Ile, respectively: (a) $\left[d_{0}\right]$-DMPITC labeled IDR, (b) $\left[d_{0}\right]$-DMPITC labeled LDR fragment ions of [DMPITC $+\mathrm{H}^{+}$at $m / z 198.0$ and $\left[\mathrm{b}_{1}-\right.$ $\mathrm{CO}^{+}$at $\mathrm{m} / z \quad 283.1$ were measured as 0.16 and 0.73 , respectively, which showed a big difference at the optimized collision energy of $20 \%$. Not coincidently, the excellent reproducibility of the relative abundance ratios has also been confirmed by five repeated experiments with relative standard deviations of $6.2 \%$ and $8.3 \%$, respectively. Besides, as shown in Table 1 , more $\left[d_{0}\right]$-DMPITC labeled peptides LVTDLTK, LVNELTEFAK, LVTDLTKVHK, LR, and IETMR with N-terminally isomeric residues separated from BSA digest were subjected to the $\mathrm{MS}^{3}$ experiment. All the $\mathrm{b}_{1}$ ions of these peptides yielded the fragment ions between $\mathrm{m} / \mathrm{z}$ 198.0 and 283.1 with rational abundance ratios (errors were all below $\pm 8.5 \%$ ) in $\mathrm{MS}^{3}$, indicating the availability of this method in differentiating N-terminal Ile and Leu residues. We preliminarily inferred such interesting distinct results for Leu and Ile residues were induced by the steric hinderance effect of slightly different methyl branches in the isomers. Further investigation is still on-going in our laboratory, which might account for the mechanism in detail.

Table 1. Relative Abundance Ratios Between the Fragment Ions at $\mathrm{m} / \mathrm{z}$ 198.0 and 283.1 from the $b_{1}$ Ions of $\left[d_{0}\right]$-DMPITC Labeled Peptides

\begin{tabular}{lccr}
\hline Peptide sequences & Observed ratio & Expected ratio & Error \% \\
\hline LVTDLTK & 0.74 & 0.73 & 1.4 \\
LVNELTEFAK & 0.69 & 0.73 & -5.5 \\
LVTDLTKVHK & 0.79 & 0.73 & 8.2 \\
LR & 0.76 & 0.73 & 4.1 \\
IETMR & 0.17 & 0.16 & 6.3 \\
\hline
\end{tabular}




\section{Validating DMPITC by Trypsin-Digested Protein}

The labeling efficiency of DMPITC for the mixture of peptides was further examined by trypsin-digested BSA. Table 2 summarizes the results from the MS/MS analysis of digested peptides. The majority of the peptides were tagged with the labeling reagent at N-terminus with little discrepancy, indicating the great labeling capacity of DMPITC. The combination of 'light' and 'heavy' labeled samples produced a visualized difference of $6 \mathrm{Da}$ (singly charged) or $3 \mathrm{Da}$ (doubly charged) in MS detection, making the digested peptides easily to be recognized. Clearly, increasing the number of detectable peptides enhanced protein sequence coverage and improved the accuracy of protein identification. Both light and heavy DMPITC gave rise to similar labeling results, which were unaffected by the presence of proteolytic enzymes, e.g. trypsin, and strong denaturants, e. g. urea. As stated above, the charge state of intact peptides was basically unchanged by the labeling reagent during the process of ionization. Besides, although PITC analogs could

Table 2. Summary of $\left[d_{0}\right]-/\left[d_{6}\right]$-DMPITC Labeled Peptides from TrypsinDigested BSA

\begin{tabular}{|c|c|c|c|c|c|}
\hline \multicolumn{5}{|c|}{$m / z$ (Monoisotopic) and charges ${ }^{\mathrm{a}}$} & \multirow[t]{3}{*}{ Peptide sequences } \\
\hline \multirow[t]{2}{*}{ Unlabeled } & & \multicolumn{3}{|c|}{ DMPITC labeled } & \\
\hline & & {$\left[d_{0}\right]$} & {$\left[d_{6}\right]$} & & \\
\hline 712.4 & 1 & 455.2 & 458.2 & 2 & SEIAHR \\
\hline 582.3 & 2 & 680.8 & 683.9 & 2 & LVNELTEFAK \\
\hline 545.3 & 1 & 742.4 & 748.4 & 1 & VASLR \\
\hline 658.3 & 1 & 855.4 & 861.4 & 1 & QEPER \\
\hline 462.2 & 1 & 659.3 & 665.3 & 1 & ADEK \\
\hline 269.1 & 2 & 367.7 & 370.7 & 2 & FWGK \\
\hline 649.3 & 1 & 846.4 & 852.4 & 1 & IETMR \\
\hline 495.8 & 2 & 594.3 & 597.3 & 2 & EKVLTSSAR \\
\hline 733.4 & 1 & 930.5 & 936.5 & 1 & VLTSSAR \\
\hline 303.2 & 1 & 500.2 & 506.3 & 1 & $\mathrm{QR}$ \\
\hline 572.4 & 1 & 769.4 & 775.4 & 1 & QRLR \\
\hline 288.2 & 1 & 485.2 & 491.3 & 1 & LR \\
\hline 508.3 & 1 & 705.3 & 711.3 & 1 & FGER \\
\hline 689.4 & 1 & 886.4 & 892.4 & 1 & AWSVAR \\
\hline 573.3 & 2 & 671.8 & 674.9 & 2 & AWSVARLSQK \\
\hline 391.2 & 1 & $\mathrm{ND}^{\mathrm{b}}$ & $\mathrm{ND}^{\mathrm{b}}$ & & FPK \\
\hline 922.5 & 1 & 1119.5 & 1125.6 & 1 & AEFVEVTK \\
\hline 789.5 & 1 & 986.5 & 992.5 & 1 & LVTDLTK \\
\hline 577.4 & 2 & 675.9 & 678.9 & 2 & LVTDLTKVHK \\
\hline 517.3 & 1 & 714.3 & 720.4 & 1 & ADLAK \\
\hline 752.4 & 1 & 949.4 & 955.4 & 1 & NYQEAK \\
\hline 862.4 & 2 & 960.9 & 964.0 & 2 & DAFLGSFLYEYSRR \\
\hline 720.4 & 2 & 818.9 & 821.9 & 2 & RHPEYAVSVLLR \\
\hline 653.4 & 2 & 751.9 & 754.9 & 2 & HLVDEPQNLIK \\
\hline 439.2 & 1 & 636.3 & 642.3 & 1 & YTR \\
\hline 820.5 & 2 & 919.0 & 922.0 & 2 & KVPQVSTPTLVEVSR \\
\hline 404.3 & 1 & 601.3 & 607.3 & 1 & SLGK \\
\hline 432.3 & 1 & 629.3 & 635.3 & 1 & VGTR \\
\hline 330.7 & 2 & 429.2 & 432.2 & 2 & TPVSEK \\
\hline 609.3 & 1 & 806.3 & 812.4 & 1 & AFDEK \\
\hline 388.3 & 1 & 585.3 & 591.3 & 1 & QIK \\
\hline 507.8 & 2 & 606.3 & 609.4 & 2 & QTALVELLK \\
\hline 818.4 & 1 & 1015.5 & 1021.5 & 1 & ATEEQLK \\
\hline 501.8 & 2 & $\mathrm{ND}^{\mathrm{b}}$ & $\mathrm{ND}^{\mathrm{b}}$ & & LVVSTQTALA \\
\hline
\end{tabular}

${ }^{\mathrm{a}}$ Major charge state

${ }^{\mathrm{b}}$ Not detected react with the $\varepsilon$-amino of lysine residues in peptides, doubly labeled peptides were not observed under the mildly experimental condition. We inferred that the $\varepsilon$-amino of lysine residue was probably protonated because of its high basicity (especially when there was a carboxyl nearby), leading to a lower reactivity than the $\alpha$-amino of $\mathrm{N}$-terminus. On the other hand, the $\mathrm{N}$-terminally specific $\mathrm{b}_{1}$ ions in MS/MS still are capable of identifying whether the labeling site is $\alpha$-amino of $\mathrm{N}$-terminus or $\varepsilon$-amino of lysine residue.

Our established strategy of N-terminus identification was also successfully accomplished on the peptides of trypsindigested BSA. As shown in Figure 5, three representative peptides (HLVDEPQNLIK ${ }^{2+}$, ADLAK ${ }^{+}$, and $\mathrm{LVTDLTK}^{+}$) labeled by $\left[d_{0}\right]-/\left[d_{6}\right]$-DMPITC simultaneously were subjected to MS/MS analysis. The intensities of their $b_{1}$ ions with 6 Da mass difference were comprehensively promoted by DMPITC, while not sacrificing the information deduced from the fragmentation of other peptide bonds. As a consequence, the identities for N-terminal residues of each peptide were elucidated as His, Ala, and Leu, respectively, using mass differences (137 Da, $71 \mathrm{Da}$, and $113 \mathrm{Da})$ between their corresponding $b_{1}$ ions and reporter ions. Leu residue at N-terminus of peptide LVTDLTK was unambiguously confirmed by the relative abundance ratio $(0.74)$ between fragment ions at $m / z 198.0$ and 283.1 from $b_{1}$ ion at the collision energy of $20 \%$. Other sequential y or b ions generated in MS/MS were conveniently assigned on the basis of the 6 Da mass deviations between heavy and light forms. There was no obvious difference between the fragmentation behavior of the multiply charged analytes and singly charged ones, which enabled DMPITC to be applied in diversified soft ionization techniques, e.g., electrospray ionization (ESI) and matrix-assisted laser desorption ionization (MALDI). Moreover, it was also found that the enhancement of $b_{1}$ ions in the MS/MS spectra of other N-terminally DMPITC labeled peptides. Coupling these advantages, DMPITC-based labeling strategy really enhances the credibility of N-terminus identification and peptide sequencing, in favor of the easy interpretation of proteins.

\section{Application of DMPITC in Comparative Protein Analysis}

Stable isotope labeling (SIL) strategy is widely considered as an effective approach for comparative protein analysis in MS-based proteomics [39-44]. The labeled target is straightforwardly investigated according to the intensity difference between light and heavy forms in MS spectrum. Here, we demonstrated the DMPITC-based SIL strategy towards comparative analysis of in vitro protein using ESIMS. Two peptide mixtures of trypsin-digested BSA were labeled by $\left[d_{0}\right]$ - and $\left[d_{6}\right]$-DMPITC, respectively. They were subsequently combined in different mixing ratios, ranging from $0.2: 1$ to $5: 1$, to generate peptide mixtures containing both light and heavy DMPITC labeled peptides. The liquid 

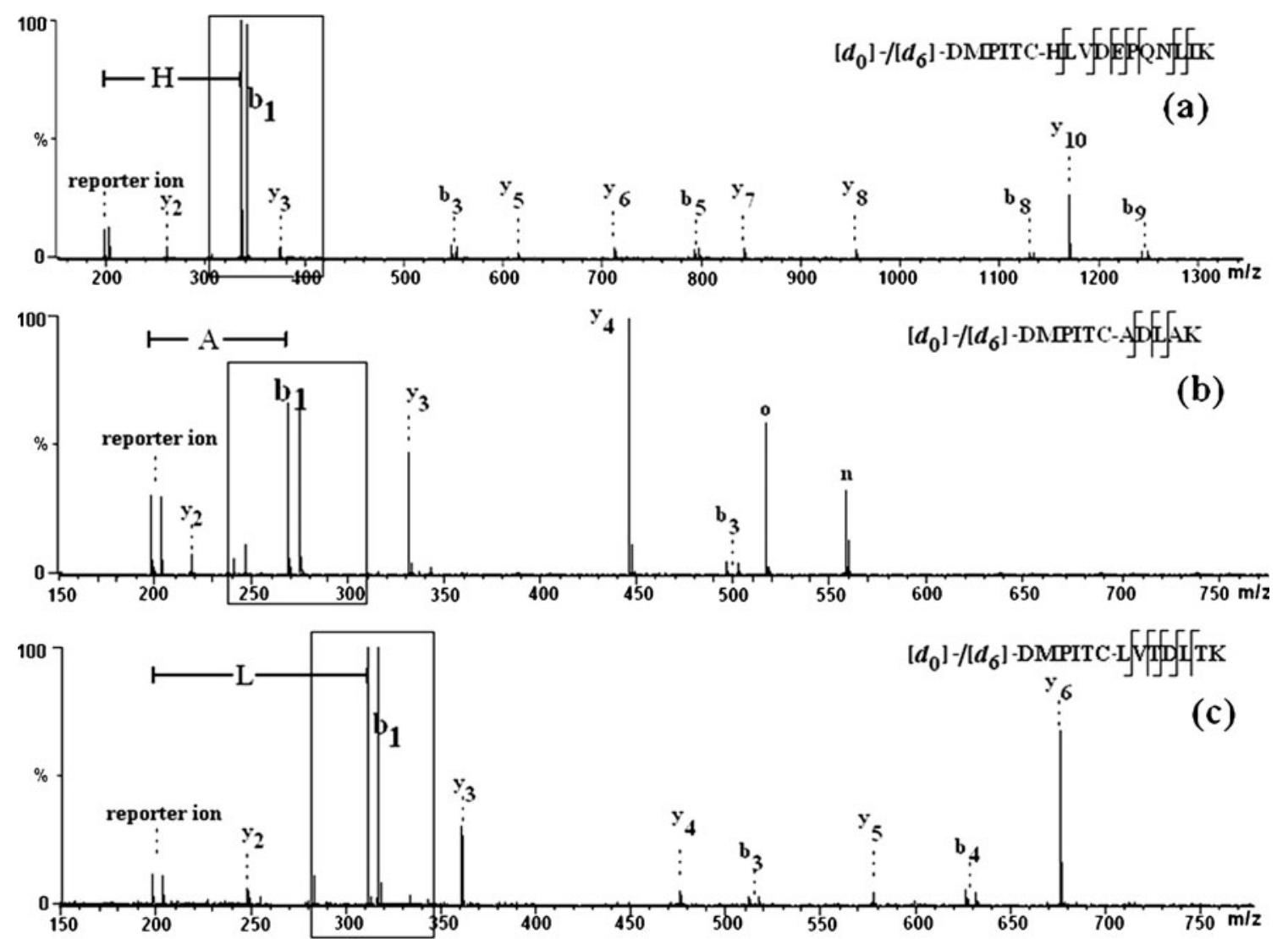

Figure 5. Overlaid MS/MS spectra of the peptides from trypsin-digested BSA: (a) $\left[d_{0}\right]-/\left[d_{6}\right]$-DMPITC labeled HLVDEPQNLIK, (b) $\left[d_{0}\right]-/\left[d_{6}\right]$-DMPITC labeled ADLAK, (c) $\left[d_{0}\right]-/\left[d_{6}\right]$-DMPITC labeled LVTDLTK (the boxes highlight $\mathrm{b}_{1}$ ions)

chromatography step was eliminated to avoid the differential elution of identical peptides labeled with the isotope pairs in chromatographic separations, which simplified the analytical procedure.

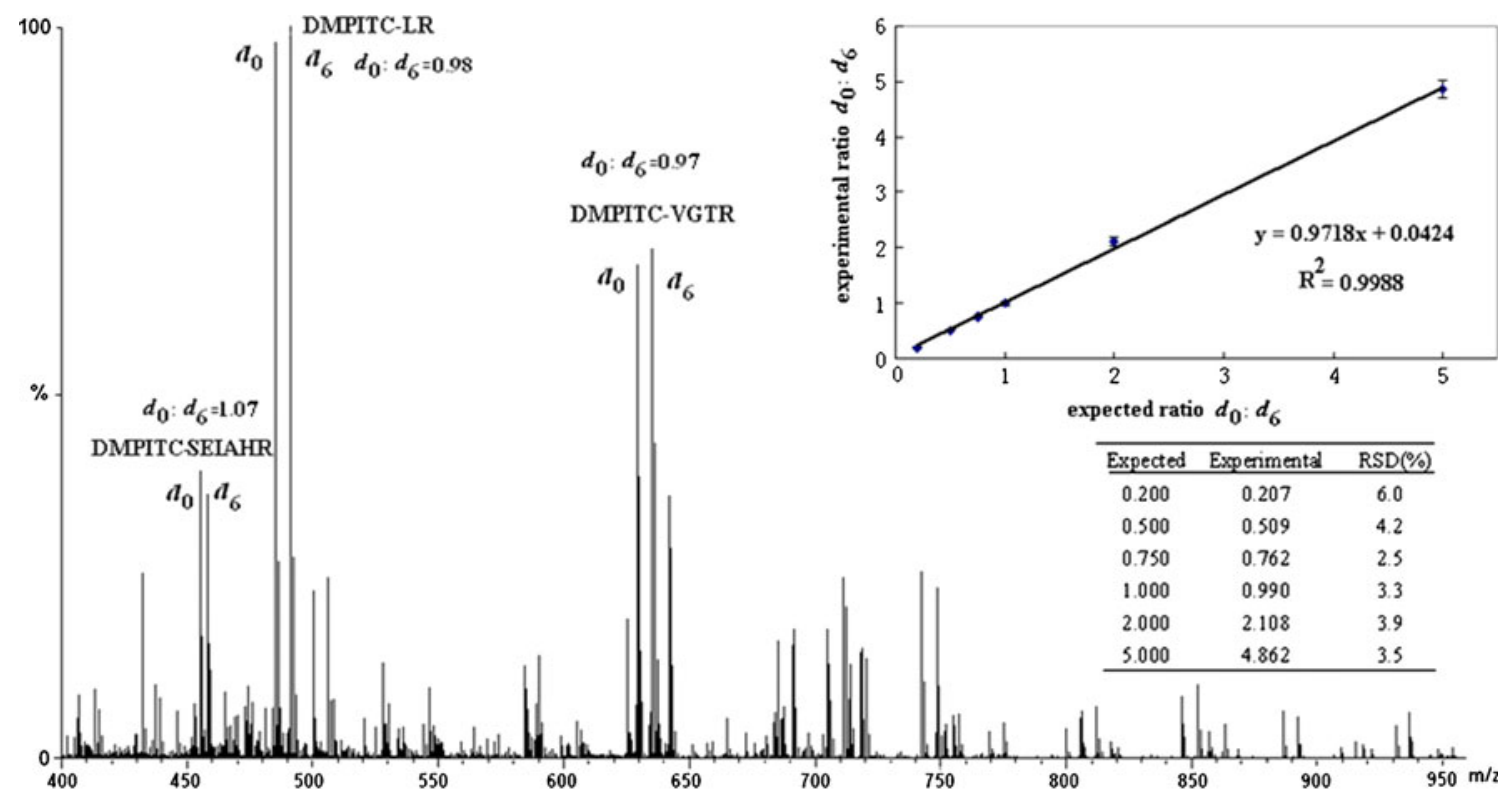

Figure 6. Mass spectrum of DMPITC labeled peptides mixture $\left(d_{0}: d_{6} \quad 1: 1\right)$ of trypsin-digested BSA and the summary of comparative protein analysis 
errors. Inset in Figure 6 shows the favorable linearity $\left(\mathrm{R}^{2}=\right.$ 0.9988) and reproducibility of DMPITC-based isotope quantitative results by MS data. The relative standard deviations of the experimental ratios $(n=3)$ ranged from ca. $6.0 \%$ for the $0.2: 1$ mixture to ca. $3.5 \%$ for the $5: 1$ mixture. For the proteolysis of proteins, digested peptides with unbalanced MS abundance ratios were observed in most cases, which led to a perfect feasibility of our quantitative strategy based on high abundance peptides. The sufficient proteolysis of target protein also needs to be ensured in order to avoid the influence of residual protein. The established strategy is not limited to a certain type of peptides (e.g., ICAT requires for cysteine residues) that gives rise to more quantitative information based on direct MS analysis. Owing to the higher polarity of DMPITC than PITC, DMPITCbased labeling strategy has little impact on the extraction of the hydrophilic analytes, reflecting more authentic quantitative results. Moreover, the desirable priority of DMPITC in enhancing sensitivity is also expected to widen the application scope to trace detection of in vivo proteins. Hence, it is worth noting that the DMPITC-based strategy is really adaptable to the relative quantification for proteins with lossless credibility and efficiency.

\section{Conclusions}

As a versatile reagent, DMPITC comprehensively demonstrated its superior performances in mass spectrometry-based proteomics. In our method, the labeling reagent was synthesized conveniently by a mild and economical route. Compared with conventional labeling reagent PITC, except owning to the capacities of rapid and N-terminally specific labeling, DMPITC also remarkably enhanced the sensitivity of target peptides in MS. More importantly, the intensity of $\mathrm{b}_{1}$ ions was promoted by DMPITC to a large extent in MS/ MS, following with the complementary sequence information such as the sequential y ions for peptide sequencing. Integrated with the validations of isotope and MS/MS/MS based on the high-yield $b_{1}$ ions, N-terminal residues of peptides were identified with a high accuracy. In addition, the DMPITC-based labeling strategy was also adapted to quantitative analysis of protein with a satisfactory efficiency and credibility. Further application of this strategy to more complex mixtures is still in progress, which is expected to serve as a potential tool for proteome research.

\section{Acknowledgments}

The authors acknowledge financial support from the National Natural Science Foundation of China (20875097, 20805056, 20902104, and 21072215), the Ministry of Science and Technology of China (2009IM031300, 2010IM030900), Chinese Academy of Sciences (YZ200938), Shanghai Basic Research Key Project (09JC1417200).

\section{References}

1. Summerfield, S.G., Bolgar, M.S., Gaskell, S.J.: Promotion and Stabilization of $b_{1}$ Ions in Peptide Phenylthiocarbamoyl Derivatives: Analogies with Condensed-phase Chemistry. J. Mass Spectrom. 32, 225-231 (1997)

2. Summerfield, S.G., Steen, H., O'Malley, M., Gaskell, S.J.: Phenyl Thiocarbamoyl and Related Derivatives of Peptides: Edman Chemistry in the Gas Phase. Int. J. Mass Spectrom. 188, 95-103 (1999)

3. Hsu, J.L., Huang, S.Y., Shiea, J.T., Huang, W.Y., Chen, S.H.: Beyond Quantitative Proteomics: Signal Enhancement of the $a_{1}$ Ion as a Mass Tag for Peptide Sequencing Using Dimethyl Labeling. J. Proteome Res. 4, 101-108 (2005)

4. Liu, N., Chan, W., Lee, K.C., Cai, Z.W.: A Method to Enhance $a_{1}$ Ions and Application for Peptide Sequencing and Protein Identification. J. Am. Soc. Mass Spectrom. 20, 1214-1223 (2009)

5. Wilkins, M.R., Gasteiger, E., Tonella, L., Ou, K., Tyler, M., Sanchez, J. C., Gooley, A.A., Walsh, B.J., Bairoch, A., Appel, R.D., Williams, K. L., Hochstrasser, D.F.: Protein Identification with N- and C-terminal Sequence Tags in Proteome Projects. J. Mol. Biol. 278, 599-608 (1998)

6. Ji, C., Guo, N., Li, L.: Differential Dimethyl Labeling of N-Termini of Peptides After Guanidination for Proteome Analysis. J. Proteome Res. 4, 2099-2108 (2005)

7. Fu, Q., Li, L.: De Novo Sequencing of Neuropeptides Using Reductive Isotopic Methylation and Investigation of ESI QTOF MS/MS Fragmentation Pattern of Neuropeptides with N-Terminal Dimethylation. Anal. Chem. 77, 7783-7795 (2005)

8. Chacon, A., Masterson, D.S., Yin, H.Y., Liebler, D.C., Porter, N.A.: NTerminal Amino Acid Side-Chain Cleavage of Chemically Modified Peptides in the Gas Phase: A Mass Spectrometry Technique for NTerminus Identification. Bioorg. Med. Chem. 14, 6213-6222 (2006)

9. Shen, P.T., Hsu, J.L., Chen, S.H.: Dimethyl Isotope-coded Affinity Selection for the Analysis of Free and Blocked N-Termini of Proteins Using LC-MS/MS. Anal. Chem. 79, 9520-9530 (2007)

10. Yamaguchi, M., Obama, T., Kuyama, H., Nakayama, D., Ando, E., Okamura, T.A., Ueyama, N., Nakazawa, T., Norloka, S., Nishimura, O., Tsunasawa, S.: Specific Isolation of N-Terminal Fragments from Proteins and Their High-fidelity De Novo Sequencing. Rapid Commun. Mass Spectrom. 21, 3329-3336 (2007)

11. Hsu, J.L., Chen, S.H., Li, D.T., Shi, F.K.: Enhanced a Fragmentation for Dimethylated Proteins and Its Applications for N-terminal Identification and Comparative Protein Quantitation. J. Proteome Res. 6, 2376-2383 (2007)

12. Nakazawa, T., Yamaguchi, M., Okamura, T., Ando, E., Nishimura, O., Tsunasawa, S.: Terminal Proteomics: N- and C-Terminal Analyses for High-fidelity Identification of Proteins Using MS. Proteomics 8, 673685 (2008)

13. van der Rest, G., He, F., Emmett, M.R., Marshall, A.G., Gaskell, S.J.: Gas-Phase Cleavage of PTC-derivatized Electrosprayed Tryptic Peptides in an FT-ICR Trapped-ion Cell: Mass-based Protein Identification without Liquid Chromatographic Separation. J. Am. Soc. Mass Spectrom. 12, 288-295 (2001)

14. Brancia, F.L., Butt, A., Beynon, R.J., Hubbard, S.J., Gaskell, S.J., Oliver, S.G.: A Combination of Chemical Derivatization and Improved Bioinformatic Tools Optimizes Protein Identification for Proteomics. Electrophoresis 22, 552-559 (2001)

15. Onisko, B., Dynin, I., Requena, J.R., Silva, C.J., Erickson, M., Carter, J. M.: Mass Spectrometric Detection of Attomole Amounts of the Prion Protein by Nano LC/MS/MS. J. Am. Soc. Mass Spectrom. 18, 10701079 (2007)

16. Sanchez, A., Perez-Riverol, Y., González, L.J., Noda, J., Betancourt, L., Ramos, Y., Gil, J., Vera, R., Padrón, G., Besada, V.: Evaluation of Phenylthiocarbamoyl-Derivatized Peptides by Electrospray Ionization Mass Spectrometry: Selective Isolation and Analysis of Modified Multiply Charged Peptides for Liquid Chromatography-Tandem Mass Spectrometry Experiments. Anal. Chem 82, 8492-8501 (2010)

17. Oe, T., Maekawa, M., Satoh, R., Lee, S.H., Goto, T.: Combining $\left[{ }^{13} \mathrm{C}_{6}\right]-$ Phenylisothiocyanate and the Edman Degradation Reaction: A Possible Breakthrough for Absolute Quantitative Proteomics Together with Protein Identification. Rapid Commun. Mass Spectrom. 24, 173-179 (2010)

18. Diego, P.A.C., Bajrami, B., Jiang, H., Shi, Y., Gascon, J.A., Yao, X.D.: Site-Preferential Dissociation of Peptides with Active Chemical Modification for Improving Fragment Ion Detection. Anal. Chem. 82, 23-27 (2010) 
19. Lee, Y.H., Kim, M.S., Choie, W.S., Min, H.K., Lee, S.W.: Highly Informative Proteome Analysis by Combining Improved N-Terminal Sulfonation for De Novo Peptide Sequencing and Online Capillary Reverse-Phase Liquid Chromatography/Tandem Mass Spectrometry. Proteomics 4, 1684-1694 (2004)

20. Johnson, R.S., Martin, S.A., Biemann, K., Stults, J.T., Watson, J.T.: Novel Fragmentation Process of Peptides by Collision-Induced Decomposition in a Tandem Mass Spectrometer: Differentiation of Leucine and Isoleucine. Anal. Chem. 59, 2621-2625 (1987)

21. Nakamura, T., Nagaki, H., Ohki, Y., Kinoshita, T.: Differentiation of Leucine and Isoleucine Residues in Peptides by Consecutive Reaction Mass Spectrometry. Anal. Chem. 62, 311-313 (1990)

22. Ramsay, S.L., Steinborner, S.T., Waugh, R.J., Dua, S., Bowie, J.H.: A Simple Method for Differentiating Leu and Ile in Peptides. The Negative-Ion Mass Spectra of $[\mathrm{M}-\mathrm{H}]^{-}$Ions of Phenylthiohydantoin Leu and Ile. Rapid Commun. Mass Spectrom. 9, 1241-1243 (1995)

23. Hulst, A.G., Kientz, C.E.: Differentiation Between the Isomeric Amino Acids Leucine and Isoleucine Using Low-Energy Collision-Induced Dissociation Tandem Mass Spectroscopy. J. Mass Spectrom. 31, 11881190 (1996)

24. Seymour, J.L., Turecek, F.: Distinction and Quantitation of LeucineIsoleucine Isomers and Lysine-Glutamine Isobars by Electrospray Ionization Tandem Mass Spectrometry $\left(\mathrm{MS}^{(n)}, n=2,3\right)$ of Copper (II)-Diimine Complexes. J. Mass Spectrom. 3, 566-571 (2000)

25. Armirotti, A., Millo, E., Damonte, G.: How to Discriminate Between Leucine and Isoleucine by Low Energy ESI-TRAP MSn. J. Am. Soc. Mass Spectrom. 18, 57-63 (2007)

26. Soltwisch, J., Dreisewerd, K.: Discrimination of Isobaric Leucine and Isoleucine Residues and Analysis of Post-Translational Modifications in Peptides by MALDI In-Source Decay Mass Spectrometry Combined with Collisional Cooling. Anal. Chem. 82, 5628-5635 (2010)

27. Zhang, J., Guo, Y.L.: A Novel Modification Reagent for Proteins: Monitoring by Matrix-assisted Laser Desorption/Ionization Time-offlight Mass Spectrometry. Rapid Commun. Mass Spectrom. 19, 24612464 (2005)

28. Zhang, J., Zhang, L., Zhou, Y., Guo, Y.L.: A Novel Pyrimidine-Based Stable-Isotope Labeling Reagent and Its Application to Quantitative Analysis Using Matrix-assisted Laser Desorption/Ionization Mass Spectrometry. J. Mass Spectrom. 42, 1514-1521 (2007)

29. Fang, F., Zhang, J., Zhang, L., Guo, Y.L.: A Stable Isotopic Predigestion Labeling Method for Protein Quantitative Analysis Using Matrix-assisted Laser Desorption/Ionization Mass Spectrometry. Chin. J. Chem. 27, 2397-2404 (2009)

30. Fang, F., Liu, P., Wang, H.Y., Zhang, L., Zhang, J., Gao, Y.P., Zeng, L. M., Guo, Y.L.: Studies of Keratins in Tongue Coating Samples of Hepatitis B Patients by Mass Spectrometry. Rapid Commun. Mass Spectrom. 23, 1703-1709 (2009)

31. Okajima, N., Aoki, I., Kuragano, T., Okada, Y.: Synthesis and Herbicidal Activity of 2-(1,3-Dimethyl-4-Substituted-5-Pyrazolyl) Sulfonylimino-5,7-Disubstututed-2 H-1,2,4-Thiadiazolo2,3- $\alpha$-Pyrimidine Derivatives. Pestic. Sci. 32, 91-104 (1991)
32. Jefferson, E.A., Seth, P.P., Robinson, D.E., Winter, D.K., Miyaji, A., Osgood, S.A., Swayze, E.E., Risen, L.M.: Biaryl Guanidine Inhibitors of In Vitro HCV-IRES Activity. Bioorg. Med. Chem. Lett. 14, 51395143 (2004)

33. Wang, H.Y., Zhang, X., Guo, Y.L., Lu, L.: Mass Spectrometric Studies of the Gas Phase Retro-Michael Type Fragmentation Reactions of 2Hydroxybenzyl-N-Pyrimidinylamine Derivatives. J. Am. Soc. Mass Spectrom. 16, 1561-1573 (2005)

34. Wang, H.Y., Zhang, X., Guo, Y.L., Tang, Q.H., Lu, L.: Using Tandem Mass Spectrometry to Predict Chemical Transformations of 2-Pyrimidinyloxy-N-Arylbenzyl Amine Derivatives in Solution. J. Am. Soc. Mass Spectrom. 17, 253-263 (2006)

35. Wang, D.X., Fang, S.A., Wohlhueter, R.M.: N-Terminal Derivatization of Peptides with Isothiocyanate Analogues Promoting Edman-Type Cleavage and Enhancing Sensitivity in Electrospray Ionization Tandem Mass Spectrometry Analysis. Anal. Chem. 81, 1893-1900 (2009)

36. Lee, Y.H., Han, H., Chang, S.B., Lee, S.W.: Isotope-coded N-terminal Sulfonation of Peptides Allows Quantitative Proteomic Analysis with Increased De Novo Peptide Sequencing Capability. Rapid Commun. Mass Spectrom. 18, 3019-3027 (2004)

37. Noga, M.J., Asperger, A., Silberring, J.: N-Terminal H-3/D-3-Acetylation for Improved High-Throughput Peptide Sequencing by Matrix-Assisted Laser Desorption/Ionization Mass Spectrometry with a Time-of-flight/ Time-of-Flight Analyzer. Rapid Commun. Mass Spectrom. 20, 1823-1827 (2006)

38. Hennrich, M.L., Mohammed, S., Altelaar, A.F.M., Heck, A.J.R.: Dimethyl Isotope Labeling Assisted De Novo Peptide Sequencing. $J$. Am. Soc. Mass Spectrom. 21, 1957-1965 (2010)

39. Heller, M., Mattou, H., Menzel, C., Yao, X.D.: Trypsin Catalyzed O-16-to-O-18 Exchange for Comparative Proteomics: Tandem Mass Spectrometry Comparison Using MALDI-TOF, ESI-QTOF, and ESIIon Trap Mass Spectrometers. J. Am. Soc. Mass Spectrom. 14, 704-718 (2003)

40. Schmidt, F., Donahoe, S., Hagens, K., Mattow, J., Schaible, U.E., Kaufmann, S.H.E., Aebersold, R., Jungblut, P.R.: Complementary Analysis of the Mycobacterium Tuberculosis Proteome by Two-dimensional Electrophoresis and Isotope-Coded Affinity Tag Technology. Mol. Cell. Proteom. 3, 24-42 (2004)

41. Schmidt, A., Kellermann, J., Lottspeich, F.: A Novel Strategy for Quantitative Proteomics Using Isotope-Coded Protein Labels. Proteomics 5, 4-15 (2005)

42. Wu, W.W., Wang, G.H., Baek, S.J., Shen, R.F.: Comparative Study of Three Proteomic Quantitative Methods, DIGE, cICAT, and iTRAQ, Using 2D Gel- or LC-MALDI TOF/TOF. J. Proteome Res. 5, 651-658 (2006)

43. Chong, P.K., Gan, C.S., Pham, T.K., Wright, P.C.: Isobaric Tags for Relative and Absolute Quantitation (iTRAQ) Reproducibility: Implication of Multiple Injections. J. Proteome Res. 5, 1232-1240 (2006)

44. Bateman, R.J., Munsell, L.Y., Chen, X.H., Holtzman, D.M., Yarasheski, K.E.: Stable Isotope Labeling Tandem Mass Spectrometry (SILT) to Quantify Protein Production and Clearance Rates. J. Am. Soc. Mass Spectrom. 18, 997-1006 (2007) 